\title{
The challenges of strategic purchasing of healthcare services in Iran Health Insurance Organization: a qualitative study
}

Hasan Abolghasem Gorji ${ }^{1,2}$, Sayyed Masoud Shajari Pour Mousavi ${ }^{3,4,5}$, Ali Shojaei ${ }^{6,7}$, Anahita Keshavarzi ${ }^{8}$, Hossein Zare $^{9}$

${ }^{1}$ Associate Professor, Health Management and Economics Research Center, Iran University of Medical Sciences, Tehran, Iran

${ }^{2}$ Department of Health Services Management, School of Health Management and Information Sciences, Iran University of Medical Sciences, Tehran, Iran

${ }^{3} \mathrm{PhD}$ Student, Health Management and Economics Research Center, Iran University of Medical Sciences, Tehran, Iran

${ }^{4}$ Department of Health Services Management, School of Health Management and Information Sciences, Iran University of Medical Sciences, Tehran, Iran

${ }^{5}$ Iran Health Insurance Organization, Tehran, Iran

${ }^{6}$ GP, MPH, PhD Student, Department of Health Policy, School of Public Health, Tehran University of Medical Sciences, Tehran, Iran

${ }^{7}$ Member of the Board of Iran Health Insurance Organization, Tehran, Iran

${ }^{8} \mathrm{GP}, \mathrm{MPH}, \mathrm{PhD}$ - Deputy Director of Health Insurance, Iran Health Insurance Organization, Tehran, Iran

${ }^{9} \mathrm{RN}, \mathrm{PhD}$, Post-Doc, Assistant Professor, Department of Health Management and Policy, University of Maryland, United States of America

\section{Type of article: Original}

\begin{abstract}
Background: Strategic purchasing in healthcare services is a key component in improving health system performance, and it has been one of the most important issues in health system reform around the world, especially Europe in the last decade. Iran health system and insurance, although sometimes considered the issue of strategic purchasing goals, has not been made possible to achieve or even to implement, due to the associated problems.

Objective: To determine the associated problems of strategic purchasing in the Iran Health Insurance Organization (IHIO).

Methods: This study is a qualitative study, and framework analysis which was conducted in Iran in 2014-15. The participants in this study were 34 individuals from decision-makers and executives in the IHIO purchasing process, and university experts who have been chosen purposefully. This study conducted frame analysis, by using MAXQDA 10.

Results: The findings included associated problems of IHIO strategic purchasing in 12 themes and 65 subthemes. The themes included: Laws and regulations for purchasing, Organization of purchasing, Qualified and authorized providers, Right type of services, Right type of contracts, Target groups for purchasing, Resources allocation, financing and pricing system, Purchasing as improving performance and quality, Purchasing as shaping the market and competition, Purchasing as health progress state of people and society, Guided purchasing and stewardship of government, Structure of decision-making process in the health and welfare ministries.

Conclusion: The findings of this study showed associated problems in IHIO strategic purchasing. To achieve strategic purchasing goals in Iran, identification of all issues and factors of the total insurers and health system sets which affect strategic purchasing is essential.
\end{abstract}

Keywords: Health insurance, Strategic purchasing, Healthcare services, Qualitative study

\section{Corresponding author:}

Sayyed Masoud Shajari Pour Mousavi. Tel: +98.9131292657, Email: masoudshajaripm@gmail.com

Received: April 26, 2017, Accepted: September 27, 2017, Published: February 2018

iThenticate screening: September 28, 2017, English editing: January 10, 2018, Quality control: January 14, 2018

(C) 2018 The Authors. This is an open access article under the terms of the Creative Commons Attribution-NonCommercialNoDerivs License, which permits use and distribution in any medium, provided the original work is properly cited, the use is non-commercial and no modifications or adaptations are made. 


\section{Introduction}

Strategic Purchasing is an important component in the healthcare financing system (1), and plays as a facilitator role in Universal Health Coverage (UHC) (2-4). Purchasing is a core function of healthcare financing (5) - the process by which funds are paid to healthcare providers to deliver services (3). Purchasing can promote quality, efficiency, equity and responsiveness in health service provision if designed and undertaken strategically (6-11), and, in doing so, facilitate progress towards UHC (2-4). Strategic purchasing is a key component to improving health system performance $(3,4,12)$. Recent evidence suggests that, strategic purchasing and the separation of purchaser and provider functions has been one of the goals in recent health care reforms in the world for improving the quality of services and to create competition between providers (2-6, 12-28). Purchasing process and subsequent competition and financial incentive structure built into the contractual relationship can lead to improvements in the provision of service delivery such as cost containment, organizational efficiency and flexibility, and improved quality and accountability of services to patient needs $(4,27)$. Therefore, due to the benefits of strategic purchasing as well as the recommendations of the World Health Organization (WHO), the health care system of the various countries are trying to move from inactive to strategic purchasing (29). Traditionally, the purchasing of healthcare services has been inactive in Iran for a long time. (30). Therefore, one of the greatest challenges has been the associated problems of strategic purchasing in Iran. Some studies have shown the importance and necessity of strategic purchasing in Iran (30-39). In a study conducted by Hasanzadeh and supported by the WHO in Iran in 2007, the main theoretical elements of strategic purchasing were studied in outpatient services. In this study, the theory of health services strategic purchasing is studied along with which service should be purchased? For whom? From who? At what price, and how? (30) In another study, conducted by Bastani and Vatankhah, in Iran Medical University, 2013, a contingency model of strategic purchasing for pharmaceutical systems was designed, and proposed as a model which is used for strategic purchasing in the Iran pharmaceutical system (36). Nevertheless, in none of the related studies, have the challenges and associated problems of strategic purchasing in Iran Health Insurance Organization been addressed (IHIO). In the healthcare reform of the Islamic Republic of Iran, 2014, the strategic purchasing center was established at the IHIO, but the strategic purchasing of services was not possible because of barriers and associated problems. With the implementation of the healthcare reform plan in the second month of that year in Iran, which developed UHC goals and eight programs mainly focused on patient financial protection and access (31), it was expected that strategic purchases would help UHC strategy in order to provide more access to healthcare services, but provincial health departments of the IHIO have continued the same inactive purchasing process. This study examines the problems encountered in the strategic purchasing process in Iran. The purpose of this study was to identify the problems and barriers which prevented the implementation of strategic purchases in IHIO.

\section{Material and Methods}

The present study is a qualitative study and a content analysis, which was conducted in 2014-15. The participants in this study, were 34 people whom were chosen purposefully, and presented in Table 1. The inclusion criteria for chosen samples included: experience and knowledge in the related field, the right to decide on the purchase of services (for the staff executives of IHIO only), membership in groups or committees associated with the strategic purchasing (for the staff of IHIO only), having paper or related disseminations about the importance of healthcare strategic purchasing in Iran (for the elites of Iran medical university only), policy-makers in the field of strategic purchasing in IHIO, strategic purchasing planners and implementers in strategic purchasing process in IHIO. The exclusion criteria included those individuals who did not have sufficient information about the subject or did not wish to be interviewed. The coordination for interviews was initially carried out on the phone, and sample interviews were conducted in their places of work for the sake of comfort. The samples were selected in cascade form and different levels of the administrators, decision-makers, and policy makers who were effective in strategic purchasing process in IHIO. Sampling continued up to data saturation. Accordingly, 34 semi structured interviews, through face to face and 16 complementary interviews by telephone, were conducted in the final month of 2014 and the first three months of 2015. All interviews were recorded and then transcribed. The time for each interview was 30 to 90 minutes. All interviews were conducted by three researchers. To confirm validity of interviews, the interviews were conducted according to guidance, experiences and assistance of the supervisor and advisor of the project. To enhance reliability, findings were returned to some of the participants, and the comments were adopted. In this study, a framework and content analysis method were used. Data analysis process for identifying main themes included: data extracting and transcribing, coding, recording reflective and marginal signs, summarizing, and developing suggestions. The framework analysis which was used for health policy and this study consisted of 5 steps: Familiarization, Identifying Thematic Framework, Indexing, Charting and Mapping, and Interpretation (40). The first step in this process was, typing and saving the transcription of interviews after conduction. In the second 
step, Identifying Thematic Framework, the interview texts were examined and reviewed several times so that the researchers dominated the data. Then, the data were divided into thematic units which were related to the main theme. At next step, thematic units were reviewed, and coded relatively, so that in each of the interviews, subthemes were separated and then merged into each other and reduced. At the final step, the main themes were identified. All analyses were carried out using MAXQDA, version 10. Ethical considerations were acknowledged during interviews in collection data, which included participants' satisfaction in recoding and then transcribing the interviews.

Table 1. The number of participants, IHIO, 2015

\begin{tabular}{|l|l|l|l|l|}
\hline & Target group & Organizational level & Sample size & $\begin{array}{l}\text { Description- } \\
\text { Cascade form }\end{array}$ \\
\hline 1 & General directors of the IHIO agencies & $\begin{array}{l}\text { In the National scale, and selected at } \\
\text { provincial level }\end{array}$ & 4 & \\
\hline 2 & $\begin{array}{l}\text { Deputy and chief executive officer of } \\
\text { general department of health insurance }\end{array}$ & In province level & 2 & \\
\hline 3 & Medical records accounting & The staff level of the IHIO, Tehran & 15 & \\
\hline 4 & Supervision and evaluation & The staff level of the IHIO, Tehran & 4 & \\
\hline 5 & Financial management & The staff level of the IHIO, Tehran & 2 & \\
\hline 6 & Managers of quality services & The staff level of the IHIO, Tehran & 2 & \\
\hline 7 & General director & The staff level of the IHIO, Tehran & 1 & \\
\hline 8 & Board of directors & The staff level the IHIO, Tehran & 1 & \\
\hline 9 & $\begin{array}{l}\text { Department of health economics, school of } \\
\text { management and medical information }\end{array}$ & Iran Medical University, Tehran & 3 & \\
\hline & Total & & 34 & \\
\hline
\end{tabular}

\section{Results}

The themes and subthemes identified in the responses are presented in Table 2 . The findings of this study included 12 basic themes, and 65 subthemes on the strategic purchasing problems in IHIO.

Table 2. Strategic purchasing problems in IHIO, 2015

\begin{tabular}{|l|l|l|}
\hline & Theme & Subtheme \\
\hline 1 & $\begin{array}{l}\text { Laws and regulations } \\
\text { referred to strategic } \\
\text { purchasing }\end{array}$ & $\begin{array}{l}\text { - Article 29 of the Constitution of the Islamic Republic of Iran- The law of public health } \\
\text { insurance (1994)- } 5^{\text {th }} \text { and } 6^{\text {th }} \text { Five-Year National Development Plan and Health Insurance } \\
\text { - Instructions on the law of physicians and allied health professions services in 1996 } \\
\text { approved by the Islamic Parliament - Lack of law, regulation and instruction or rule based } \\
\text { on IHIO functions for strategic purchasing }\end{array}$ \\
\hline 2 & $\begin{array}{l}\text { Organization of the } \\
\text { strategic purchasing } \\
\text { function }\end{array}$ & $\begin{array}{l}\text { - Lack of provider and purchaser split (PPS) in several functions of the welfare and health } \\
\text { ministries- Lack of written mission in the IHIO, for strategic purchasing- Lack of } \\
\text { standard structure, and functions for IHIO related to strategic purchasing- Lack of } \\
\text { reasonable structure, process and outcome for strategic purchasing in public and private } \\
\text { sectors- Lack of strategic planning for strategic purchasing- Lack of vertical and } \\
\text { horizontal cooperation for strategic purchasing- Lack of private and public-sector } \\
\text { cooperation for strategic purchasing }\end{array}$ \\
\hline 3 & $\begin{array}{l}\text { Qualified and } \\
\text { authorized providers } \\
\text { accreditation for providers' services- Lack of standard structure, process, and outcome in } \\
\text { services providing- Lack of training, retraining, and training applications for services } \\
\text { providers- Variability in quantity and quality of provided services due to not being based } \\
\text { on proper and approved clinical protocols and guidelines- Lack of needs assessment and } \\
\text { priority setting for services providers }\end{array}$ \\
\hline 4 & $\begin{array}{l}\text { - Lack of appropriate and approved clinical protocols, guidelines, procedures, and policies } \\
\text { for services that will be purchased, it leads to a reduction in service quality levels and } \\
\text { then rising costs- Ignoring indicators of quality, efficiency, effectiveness, and safety for } \\
\text { services - Failure to use appropriate and approved standard of the structure, process, and } \\
\text { outcome in providing services- Lack of consisting 3 dimensions of coverage (group, } \\
\text { services and cost) for vulnerable groups- Lack of accessibility, affordability, availability, }\end{array}$ \\
\hline
\end{tabular}


http://www.ephysician.ir

\begin{tabular}{|c|c|c|}
\hline & & and comprehensiveness of services \\
\hline 5 & Right type of contracts & $\begin{array}{l}\text { - Not paying attention to the structure of market components and dominations in the } \\
\text { contracts- Lack of suitable incentive in the purchase- Lack of appropriate mechanisms in } \\
\text { payments and purchases }\end{array}$ \\
\hline 6 & $\begin{array}{l}\text { Target groups for } \\
\text { purchasing }\end{array}$ & $\begin{array}{l}\text { - Lack of identification of vulnerable groups for purchasing- Overlapping in groups } \\
\text { coverage by related health insurance organizations- Absent sustainable universal health } \\
\text { coverage in related health insurance organizations }\end{array}$ \\
\hline 7 & $\begin{array}{l}\text { Resources allocation, } \\
\text { financing, and pricing } \\
\text { system }\end{array}$ & $\begin{array}{l}\text { - Lack of enough financial resources to strategic purchasing accordance with volume and } \\
\text { variations of UHC in IHIO- Lack of sufficient transparency in financial resources- Lack } \\
\text { of tariff and pricing system to determine the price of services- Lack of appropriate and } \\
\text { sustainable financing system and risk assessment- Lack of attention to efficiency and } \\
\text { effectiveness in financing }\end{array}$ \\
\hline 8 & $\begin{array}{l}\text { Purchasing, as } \\
\text { improving performance } \\
\text { and quality }\end{array}$ & $\begin{array}{l}\text { - Improve the health status level of the community and especially the primary health care- } \\
\text { Increasing commitment and accountability- Improve equity and accessibility to services- } \\
\text { Improve technical and allocative efficiency, and economy in the scale- Improve the level } \\
\text { of quality, performance and effectiveness indicators of services- Empowering citizenship }\end{array}$ \\
\hline 9 & $\begin{array}{l}\text { Purchasing, as shaping } \\
\text { the market and } \\
\text { competition }\end{array}$ & $\begin{array}{l}\text { - The number and volume of the purchasers- The degree of patient choice of purchaser- } \\
\text { The degree of patient care which directly developed policy of purchaser- The degree of } \\
\text { choices involved in purchasing contracts that patients agree with- The degree of control of } \\
\text { clinical services, used by the patients, which is included in the purchasing contracts- } \\
\text { Content of services which may be variables- The terms and conditions placed in contracts } \\
\text { by purchaser and refer to how to compete with providers- Lack of competition between } \\
\text { healthcare providers as a consequent of provider and purchaser split (PPS) }\end{array}$ \\
\hline 10 & $\begin{array}{l}\text { Purchasing as health } \\
\text { progress state of people } \\
\text { and society }\end{array}$ & $\begin{array}{l}\text { - Assessment of needs, demands and responsibilities- Specify the cycle: Need assessment, } \\
\text { Determining of the care, Purchasing the care, Monitoring the outcome- Determining the } \\
\text { details of the health state problems of society- Determining the prevalence and incidence } \\
\text { for each disease- Determining the available and needed services for the community- } \\
\text { Determining the effectiveness and/or the cost-effectiveness for services delivered to the } \\
\text { community in health state related subjects- Designing appropriate health care models for } \\
\text { the community- Determining the goals, objectives, and outcome in the health status of the } \\
\text { community }\end{array}$ \\
\hline 11 & $\begin{array}{l}\text { Guided purchasing and } \\
\text { stewardship of } \\
\text { government }\end{array}$ & $\begin{array}{l}\text { - Directing the purchase by organizing-Directing the purchase by financing- Directing } \\
\text { the purchase through the appropriate payment system- Guiding the purchase through the } \\
\text { proper laws and regulations- Guiding the purchase through shaping customer behavior- } \\
\text { Stewardship as accountability and responsiveness- Stewardship and the level of } \\
\text { government participation (public, semi-public and private) }\end{array}$ \\
\hline 12 & $\begin{array}{l}\text { Structure of decision- } \\
\text { making process in the } \\
\text { health and welfare } \\
\text { ministries }\end{array}$ & - Economic barriers- Political obstacles- Social and cultural barriers \\
\hline
\end{tabular}

\subsection{Laws and regulations referred to strategic purchasing}

In this regard, participants pointed out factors such as those shown in Table 2. Participants declared that "By referring to the law, Article 29 of the Constitution states that all Iranians not in health insurance coverage (4 funds), must be insured by IHIO, therefore strategic purchasing consisted of them and not all Iranians, and does not included other health insurance such as the social security organization." (Interview no. 3). "Another issue is that of the law of public health insurance (1994), by this law, only medical services purchasing is mandatory and other health services such as preventive services are not necessary for coverage by the government from 1994 to 2013. Therefore, this issue is difficult for decision making for strategic purchasing in health services comprehensiveness" Another factor which participants stated, was "article 38 of the $5^{\text {th }}$ and $6^{\text {th }}$ Five-Year National Development Plan and Health Insurance, which implies IHIO should complete universal health coverage for the population, reducing the share of public health costs to $30 \%$. It included covering a population of nearly ten to fifteen million people, who have no insurance. Following the mission of the IHIO, this organization must cover people, who have no health insurance with wide variations by using strategic purchasing as a tool. By referring to the plan, strategic purchasing has become the policy of IHIO for the last three years. Therefore, the volume and and variations of coverage people 
can lead to difficulties in the strategic purchasing process" (Interview no. 11) "By referring to this law, instructions on the law of physicians and allied health professions services, approved by the Islamic Parliament (1996), all the medical professions who have a medical office must have a contract with IHIO, compulsorily. Therefore, this issue is quite difficult for decision making on strategic purchasing in the services selections as regards to quality." (Interview no. 25)

\subsection{Organization Of the strategic purchasing functions}

In this regard, participants declared that" In current state, health insurers, due to the lack of proper structure and strategic planning, have no mission, vision or responsibility and possibility in the arrangements for strategic purchasing. In addition, at the missions of ministries of health and welfare, there are no related items for strategic purchases in a coherent set." (Interview no. 10)

\subsection{Qualified and authorized providers}

Participants presented competency and eligibility of the healthcare provider affecting strategic purchasing in the form of the following issues. "Healthcare standards in the Iran health system are not defined annually by scientific associations or by the Ministry of Health, and have not been revised over time." (Interview no. 16) "For the most part, inappropriate diagnosis and treatment tools, inadequate physical space usually in the physician's office, or inappropriate medical equipment, or low-skilled manpower are because of non-compliance with the standard and/or appropriate clinical protocols." (Interview no. 19)

\subsection{Right type of services}

Participants proposed issues affecting strategic purchasing such as: "Lack of accessibility, affordability, availability, and comprehensiveness of services" and "ignoring indicators of quality, efficiency, effectiveness, and safety for services." (Interview no. 18) Other issues were showed in Table 2.

\subsection{Right type of contracts}

In this regard, participants pointed out issues such as those shown in Table 2.

\subsection{Target groups for purchasing}

Related items were presented in Table 2.

\subsection{Resources allocation, financing, and pricing system}

In this regard, participants declared the following issues:" Lack of enough financial resources to strategic purchasing accordance with volume and variations of UHC in IHIO, lack of sufficient transparency in financial resources, lack of tariff and pricing system to determine the price of services". (Interview no. 20).

The rest of the issues and other factors were presented in Table 2.

\section{Discussion}

An initial objective of the project was to identify the associated problems of strategic purchasing in IHIO. The most interesting findings of the strategic purchasing problems in IHIO included 12 themes and subsequently, 65 related subthemes which have prevented the achievement of strategic purchasing goals in Iran in 2016. Although the known problems were not with the same importance, the majority of the problems could be solved -which this study has shown them- such as: the lack of law and regulations on strategic purchasing, provider-purchaser spilt for purchasing system improvement as well as internal and external factors affecting the purchasing system. Considering that strategic purchasing plays a vital and facilitating role in UHC (4), and since one of the goals of the IHIO was the UHC, this organization can cover uninsured people more conveniently by solving the problems of strategic purchasing. As it was mentioned here, the recent reforms of health care systems in the world, have led to numerous changes in the organizational structure of the health system and consequently, the purchasing as a system $(3,6,12-14)$. However, it is necessary to identify and then solve problems in health strategic purchasing as a core function of financing to improve health care system performance. The findings of this study seem to be consistent with other research which found strategic purchasing problems in healthcare. For example, Raeissi et al. (2013) indicated influential factors on strategic purchasing of healthcare services in the Iranian Social Security Organization (ISSO). The factors such as: purchasing priority, allocating resources, payment mechanism, organization structure, price, contract, providers, service utilizers, and purchasing strategy were effective in strategic purchasing of healthcare services (34). These results were similar to themes one to twelve and related subthemes on the present study. Tangcharoensathien (2014), in his report, has stated that by identify purchasing associated 
problems and running strategic purchasing, as the key policy instruments to achieve the universal health coverage (UHC) goals in Thailand, objectives such as: provider purchaser spilt, financial protection, appropriate access to services and competition in the market to improve the quality level and reduce costs have been somewhat reached (7). The results were similar to theme seven and eight and related the subthemes in this study. Theme eleven of this finding, the problems associated with strategic purchasing, are closely linked with the results of the study by Marten et al. (2014), entitled "Assessment of progress towards universal health coverage in Brazil, Russia, India, China and South Africa (BRICS)". In this study, the emphasis was on regular planning for strategic purchasing, especially in the private sector, interacting and investing with public and primary health care and creating a decentralized structure of government, as a fundamental, to complete UHC (41). Katzin (2012), as an expert of the World Health Organization, stated that strategic purchasing could be introduced as a tool to improve the efficiency, effectiveness and specialization in the purchasing, which makes lessons for national health financial systems in the related countries (27). In this study, theme eight was In accordance with performance of purchasing.

\section{Conclusions}

This study has identified factors and problems associated with strategic purchasing in the IHIO. The practical application of the findings was to determine related factors and problems in strategic purchasing to resolving the involved problems. According to the findings of this study, it is suggested that a series of related decisions and actions should be taken to completing the identification process and then beginning the solving process of strategic purchasing problems in Iran. In this regard, studies are recommended to identify effective factors and problems in strategic purchasing in other health insurance organizations in Iran.

\section{Acknowledgments:}

We would like to thank all of the participants for the insightful discussions and for their availability to share their experiences and knowledge. All responsibilities for the manuscript rest with the authors. This research was funded and supported by the school of health management, Iran University of Medical Sciences, Grant No. IR.IUMS.REC 1394.9221532201 .

\section{Conflict of Interest:}

There is no conflict of interest to be declared.

Authors' contributions:

All authors contributed to this project and article equally. All authors read and approved the final manuscript.

\section{References:}

1) Organization WH. Paying for Performance in Health Care Implications for Health System Performance and Accountability: Implications for Health System Performance and Accountability: OECD Publishing; 2014.

2) Fuenzalida-Puelma HL, O’Dougherty S, Evetovits T, Cashin C, Kacevicius G, McEuen M. Purchasing of health care services. Implementing health financing reform: lessons from countries in transition Copenhagen: World Health Organization. 2010: 155-86.

3) Figueras J, Robinson R, Jakubowski E. Purchasing to improve health systems performance: drawing the lessons. Purchasing to improve health systems performance. 2005: 44.

4) Busse R, Figueras J, Robinson R, Jakubowski E. Strategic purchasing to improve health system performance: key issues and international trends. Healthc Pap. 2007; 8: 62-76. doi: 10.12927/hcpap.2007.19221. PMID: 19096267.

5) Kutzin J. A descriptive framework for country-level analysis of health care financing arrangements. Health policy. 2001; 56(3): 171-204. doi: 10.1016/S0168-8510(00)00149-4. PMID: 11399345.

6) Robinson R, Jakubowski E, Figueras J. Organization of purchasing in Europe. Purchasing to improve health systems performance. 2005: 11-43.

7) Tangcharoensathien V, Limwattananon S, Patcharanarumol W, Thammatacharee J, Jongudomsuk P, Sirilak S. Achieving universal health coverage goals in Thailand: the vital role of strategic purchasing. Health Policy Plan. 2015; 30(9): 1152-61. doi: 10.1093/heapol/czu120. PMID: 25378527, PMCID: PMC4597041.

8) Preker AS, Liu X, Velenyi EV, Baris E. Public ends, private means: strategic purchasing of health services: Washington, DC: World Bank; 2007. doi: 10.1596/978-0-8213-6547-2.

9) Munge K, Mulupi S, Barasa EW, Chuma J. A critical analysis of purchasing arrangements in Kenya: the case of the National Hospital Insurance Fund. International Journal of Health Policy and Management. 2017; 7(3): 254-44. doi: 10.15171/ijhpm.2017.81. 
10) Ashton T, Cumming J, McLean J. Contracting for health services in a public health system: the New Zealand experience. Health Policy. 2004; 69(1): 21-31. doi: 10.1016/j.healthpol.2003.11.004. PMID: 15484604.

11) Yip W, Hanson K. Purchasing health care in China: experiences, opportunities and challenges. Adv Health Econ Health Serv Res. 2009; 21: 197-218. PMID: 19791704.

12) Figueras J, Robinson R, Jakubowski E. Purchasing to improve health systems performance: McGraw-Hill Education (UK); 2005.

13) Saltman RB, Figueras J. Analyzing the evidence on European health care reforms. Health affairs. 1998; 17(2): 85-108. doi: 10.1377/hlthaff.17.2.85. PMID: 9558787.

14) Langenbrunner JC, Orosz E, Kutzin J, Wiley MM. Purchasing and paying providers. Purchasing to improve health systems performance. 2005: 236.

15) Bevan G, Van De Ven WP. Choice of providers and mutual healthcare purchasers: can the English National Health Service learn from the Dutch reforms? Health Econ Policy Law. 2010; 5(3): 343-63. doi: 10.1017/S1744133110000071. PMID: 20478105.

16) Cabiedes L, Guillén A. Adopting and adapting managed competition: health care reform in Southern Europe. Soc Sci Med. 2001; 52(8): 1205-17. doi: 10.1016/S0277-9536(00)00240-9. PMID: 11281404.

17) Carrin G, Waelkens MP, Criel B. Community - based health insurance in developing countries: a study of its contribution to the performance of health financing systems. Trop Med Int Health. 2005; 10(8): 799811. doi: 10.1111/j.1365-3156.2005.01455.x. PMID: 16045467.

18) Ford EW, Scanlon DP. Promise and problems with supply chain management approaches to health care purchasing. Health Care Manage Rev. 2007; 32(3): 192-202. doi: 10.1097/01.HMR.0000281623.35987.cf. PMID: 17666990.

19) Gilbert SB. New millennium strategic initiatives for health care purchasing. Hospital Materiel Management Quarterly. 2001; 22(3): 71.

20) Glinos IA, Baeten R, Maarse H. Purchasing health services abroad: practices of cross-border contracting and patient mobility in six European countries. Health Policy. 2010; 95(2-3): 103-12. doi: 10.1016/j.healthpol.2009.11.016. PMID: 20031249.

21) Glock CH, Hochrein S. Purchasing Organization and Design: a literature review. Business Research. 2011; 4(2): 149-91. doi: 10.1007/BF03342754.

22) Hanvoravongchai $P$. Health financing reform in Thailand: toward universal coverage under fiscal constraints. 2013.

23) Harrison MI, Calltorp J. The reorientation of market-oriented reforms in Swedish health-care. Health Policy. 2000; 50(3): 219-40. doi: 10.1016/S0168-8510(99)00060-3. PMID: 10827309.

24) Harrison S. Working the markets: purchaser/provider separation in English health care. Int J Health Serv. 1991; 21(4): 625-35. doi: 10.2190/BTXE-XGBW-BDFK-B5G6. PMID: 1769751.

25) Smith J, Lewis R, Harrison T. Making commissioning effective in the reformed NHS in England. 2006.

26) Kotler P, Shalowitz J, Stevens RJ. Strategic marketing for health care organizations: building a customerdriven health system: John Wiley \& Sons; 2011.

27) Kutzin J. Health financing for universal coverage and health system performance: concepts and implications for policy. Bull World Health Organ. 2013; 91(8): 602-11. doi: 10.2471/BLT.12.113985. PMID: 23940408, PMCID: PMC3738310.

28) Kutzin J, Jakab M, Cashin C. Lessons from health financing reform in central and eastern Europe and the former Soviet Union. Health Econ Policy Law. 2010; 5(2): 135-47. doi: 10.1017/S1744133110000010. PMID: 20226116.

29) Saksena P, Xu K, Elovainio R, Perrot J. Health services utilization and out-of-pocket expenditure at public and private facilities in low-income countries. World health report. 2010; 20: 20.

30) Hassanzadeh A. Equity, Social Security and Healthcare Strategic Purchasing. first ed. Tehran: Bahram; 2012.

31) Hassanzadeh A. The ways of Universal Health Coverage Achieving in Iran. Tehran. 2012; (32, 33). Available from ravabet $\% 20$ omomi/entesharat/faslname\%2032-33.pdf.

32) Lotfi F, Abolghasem Gorji H, Mahdavi G, Hadian M. Asymmetric information in Iranian's health insurance market: Testing of adverse selection and moral hazard. Global journal of health science. 2015; 7(6): 146. doi: 10.5539/gjhs.v7n6p146. PMID: 26153155, PMCID: PMC4803894. 
33) Pouragha B, Pourreza A, Jaafaripooyan E, Heydari H, Rahimi Froushani A, Hassanzadeh A. The effect of access and out of pocket payment on the utilization of physicians services. World Appl Sci J. 2013; 22(1): 104-12. doi: 10.5829/idosi.wasj.2013.22.01.2030.

34) Raeissi P, Nasirpour A, Karimi K, Influential Factors on Strategic Purchasing of Healthcare Services in Iran Social Security Organization- Indirect Healthcare Sector, Journal of Novel Applied Sciences, 2013;65 (73).

35) Ibrahimipour H, Maleki MR, Brown R, Gohari M, Karimi I, Dehnavieh R. A qualitative study of the difficulties in reaching sustainable universal health insurance coverage in Iran. Health Policy Plan. 2011; 26(6): 485-95. doi: 10.1093/heapol/czq084. PMID: 21303879.

36) Bastani P, Doshmangir L, Samadbeik M, Dinarvand R. Requirements and Incentives for Implementation of Pharmaceutical Strategic Purchasing in Iranian Health System: A Qualitative Study. Global Journal of Health Science. 2016; 9(1): 163. doi: 10.5539/gjhs.v9n1p163.

37) Bazyar M, Rashidian A, Kane S, Vaez Mahdavi MR, Akbari Sari A, Doshmangir L. Policy options to reduce fragmentation in the pooling of health insurance funds in Iran. Int J Health Policy Manag. 2016; 5(4): 253-8. doi: 10.15171/ijhpm.2016.12. PMID: 27239868, PMCID: PMC4818990.

38) Bigdeli M, Annear PL. Barriers to access and the purchasing function of health equity funds: lessons from Cambodia. Bull World Health Organ. 2009; 87(7): 560-4. doi: 10.2471/BLT.08.053058. PMID: 19649372, PMCID: PMC2704035.

39) Razavi SM. Impact of Structural Adjustment Programs on Health Care Financing in Iran: Brandeis University, The Heller School for Social Policy and Management; 2011.

40) Srivastava A, Thomson SB. Framework analysis: a qualitative methodology for applied policy research. JOAAG. 2009; 4(2).

41) Marten R, McIntyre D, Travassos C, Shishkin S, Longde W, Reddy S, et al. An assessment of progress towards universal health coverage in Brazil, Russia, India, China, and South Africa (BRICS). The Lancet. 2014; 384(9960): 2164-71. doi: 10.1016/S0140-6736(14)60075-1. 